\title{
CONGENITAL AORTIC STENOSIS OPERATIVE INDICATIONS AND SURGICAL RESULTS*
}

\author{
BY \\ MARTIN H. LEES, ANNE J. HAUCK, GEORGE W. B. STARKEY, \\ ALEXANDER S. NADAS, AND ROBERT E. GROSS \\ From the Department of Pediatrics and Surgery, Harvard Medical School and the Sharon Cardiovascular \\ Unit, Children's Hospital Medical Center, Boston, Massachusetts, U.S.A.
}

Received April 28, 1961

Congenital aortic stenosis is a relatively common disease. It is the one malformation predisposing to sudden death in children. Surgical attempts at correction of critical congenital aortic stenosis have been reported within recent years, but there are no large series with adequate longterm follow up of the post-operative course of children with aortic stenosis.

The present report is based on our experiences with aortic valve surgery at the Children's Hospital Medical Center, Boston during the period August 1957 to April 1960.† During this time 42 patients with congenital aortic stenosis had lesions considered severe enough to warrant corrective surgery. These patients, whose ages ranged from 6 weeks to 20 years, were all operated upon by the trans-aortic approach utilizing total cardio-pulmonary bypass (Gross, 1959) and potassium citrate cardioplegia.

This report presents the results of operation and the subsequent course as judged by clinical, electrocardiographic, radiological, and, in some instances, post-operative catheterization data.

\section{Methods of Evaluation}

A complete physical examination by at least one of the authors, cardiac fluoroscopy, radiograms, and 12 lead electrocardiograms were available in all patients pre-operatively. Right heart catheterization according to a technique described elsewhere (Rudolph and Cayler, 1958) was performed before operation in every instance. Left heart catheterization either through the transventricular approach (Brock et al., 1956) or in a retrograde fashion (Zimmerman et al., 1950; Morrow et al., 1960), through a systemic artery, was also performed in every case. Cardiac outputs, where possible, were determined during the left heart catheterization; if this was not feasible the values obtained during right heart catheterization have been utilized in the calculations.

All survivors were re-evaluated by the clinical methods cited above. In addition 13 of them were recatheterized.

\section{INDICATIONS FOR OPERATION}

We arbitrarily regarded a systolic gradient across the left ventricular outflow of $50 \mathrm{~mm} . \mathrm{Hg}$ or a mean systolic ejection gradient of $30 \mathrm{~mm}$. $\mathrm{Hg}$ as a minimum indication for surgical relief of aortic

* Supported in part by grants from the National Heart Institute, National Institutes of Health, U.S. Public Health Service HTS5310, H/623(C11), and a grant-in-aid from the American Heart Association, and the Massachusetts Heart Association. 1960.

Presented in part at the Thirty-third Scientific Session of the American Heart Association in St. Louis, October 22,

$\dagger$ Between April 1960 and February 1961 a further 12 patients have been operated upon with one further death. 
stenosis. In addition, in most instances, the patients had electrocardiographic evidence of left ventricular hypertrophy with or without S-T and T wave changes. Symptoms of chest pain, syncope, or fatigue were also present in an appreciable number of instances. These clinical features were, in fact, the basis for selecting subjects for left heart catheterization from the larger group of children with a clinical diagnosis of aortic stenosis.

TABLE I

Findings at Operation in 42 Cases of Congenital Aortic Stenosis

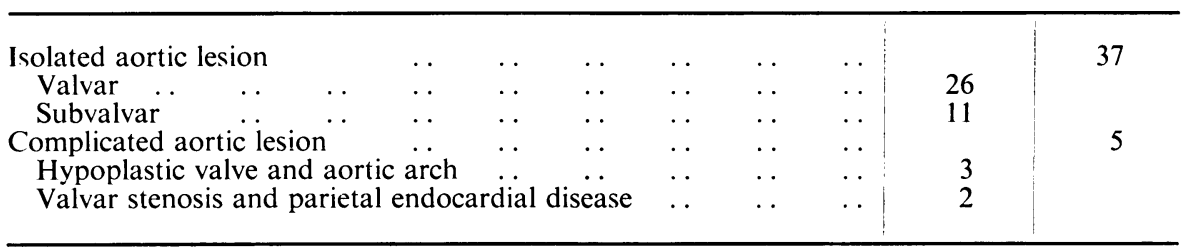

Table I shows the anatomical situation as encountered at operation. There were 37 instances where the aortic valve lesion was the only intracardiac anomaly. About two-thirds of the patients had valvar and one-third had subvalvar stenosis. Five of these had associated coarctation of the aorta, and three additional patients had had a patent ductus arteriosus divided earlier in life. The remaining 5 patients had associated intracardiac anomalies as described in Table I.

\section{Surgical Mortality}

The total mortality was 6 , representing 14 per cent. Two deaths were in critically ill infants aged 6 weeks and 2 months respectively. One patient had endocardial fibroelastosis; one had mitral valve disease with parietal endocardial sclerosis and a further death was in a patient with a hypoplastic aortic valve and ascending aorta.

The sixth death occurred in a 6-year-old boy who had a bicuspid aortic valve with fusion along the two commissures and, in addition, a subvalvar stenosis. It was felt at the time of surgery that little had been achieved. Post-operatively he did not recover consciousness and died on the eighth post-operative day. Autopsy revealed, in addition to the residual severe subvalvar aortic stenosis, a subdural hæmorrhage, ischæmic nephrosis, and terminal bronchiolitis.

\section{Post-OPERATIVE Progress}

Of the 36 survivors, 2 patients had generalized hypoplasia of the aortic arch and aortic valve; no surgical correction was possible in these two and thus they will not be considered in the survey of post-operative results. Eleven of the remaining 34 patients had subvalvar stenosis and in 23 the stenosis was valvar.

In assessing the post-operative status of these 34 patients the following parameters were considered: (1) symptomatology, (2) heart size, (3) development of aortic regurgitation, (4) electrocardiogram, and (5) left heart catheterization. The minimum follow-up was 9 months, the maximum $3 \frac{1}{2}$ years with an average of 17 months.

In Fig. 1 the post-operative changes in symptomatology, heart size, and aortic regurgitation are presented in both the valvar and subvalvar groups.

The pre-operative symptoms were, on the whole, mild, consisting of minimal dyspnœa and easy fatigueability. However, chest pain, which was in no case typical of angina, was present in 5, and 2 further patients had had syncopal attacks. There was a relief of symptoms in most of the patients in the valvar group and in some of the cases with subvalvar stenosis.

Cardiac enlargement was usually slight to moderate in both groups and so far the heart size seems little affected by operation. 
VALVAR AORTIC STENOSIS

23 CASES
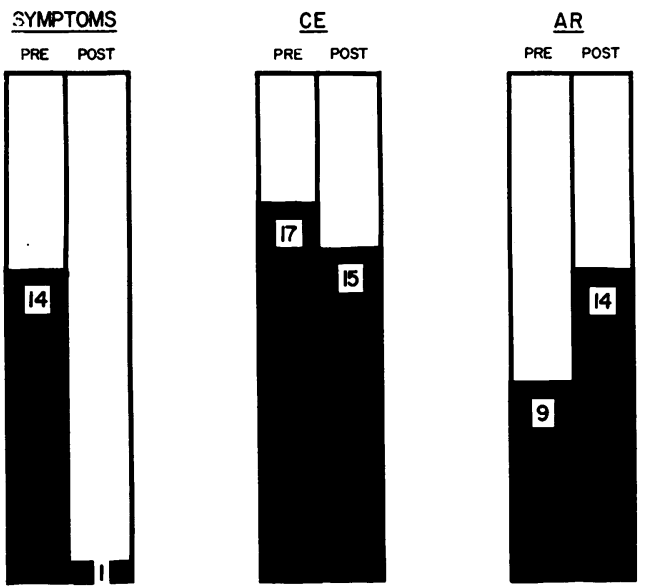

SUBVALVAR AORTIC STENOSIS

II CASES
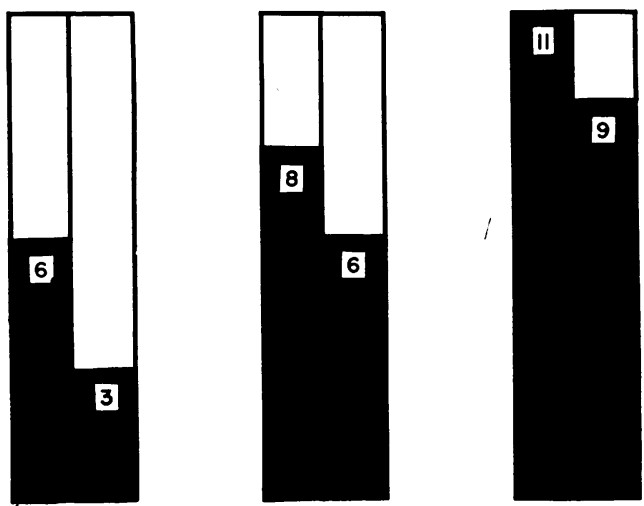

FIG. 1.-Comparison of symptoms, heart size and aortic regurgitation pre- and post-operatively in patients with valvar and subvalvar aortic stenosis.

CE-Cardiac enlargement.

AR-Aortic regurgitation.

Aortic regurgitation, as evidenced by an aortic proto-diastolic murmur, was present in 9 of the valvar stenoses, pre-operatively, and in all the cases of subvalvar stenosis.

In no case did the regurgitation seem to be hæmodynamically significant. As a matter of fact the pulse pressure in all but two patients was less than $50 \mathrm{~mm}$., and in all was less than $65 \mathrm{~mm}$. So constant has been the finding of an aortic diastolic murmur in subvalvar stenosis that we have come to regard the absence of this murmur as making the diagnosis of subvalvar stenosis very unlikely. Five of the patients with valvar stenosis have developed an aortic diastolic murmur post-operatively. In one the pulse pressure has increased from $42 \mathrm{~mm}$. Hg to $60 \mathrm{~mm}$. $\mathrm{Hg}$ but, apart from this, none has developed hæmodynamically significant aortic regurgitation. Two cases of subvalvar stenosis appear to have lost their aortic diastolic murmurs as a result of surgery. 

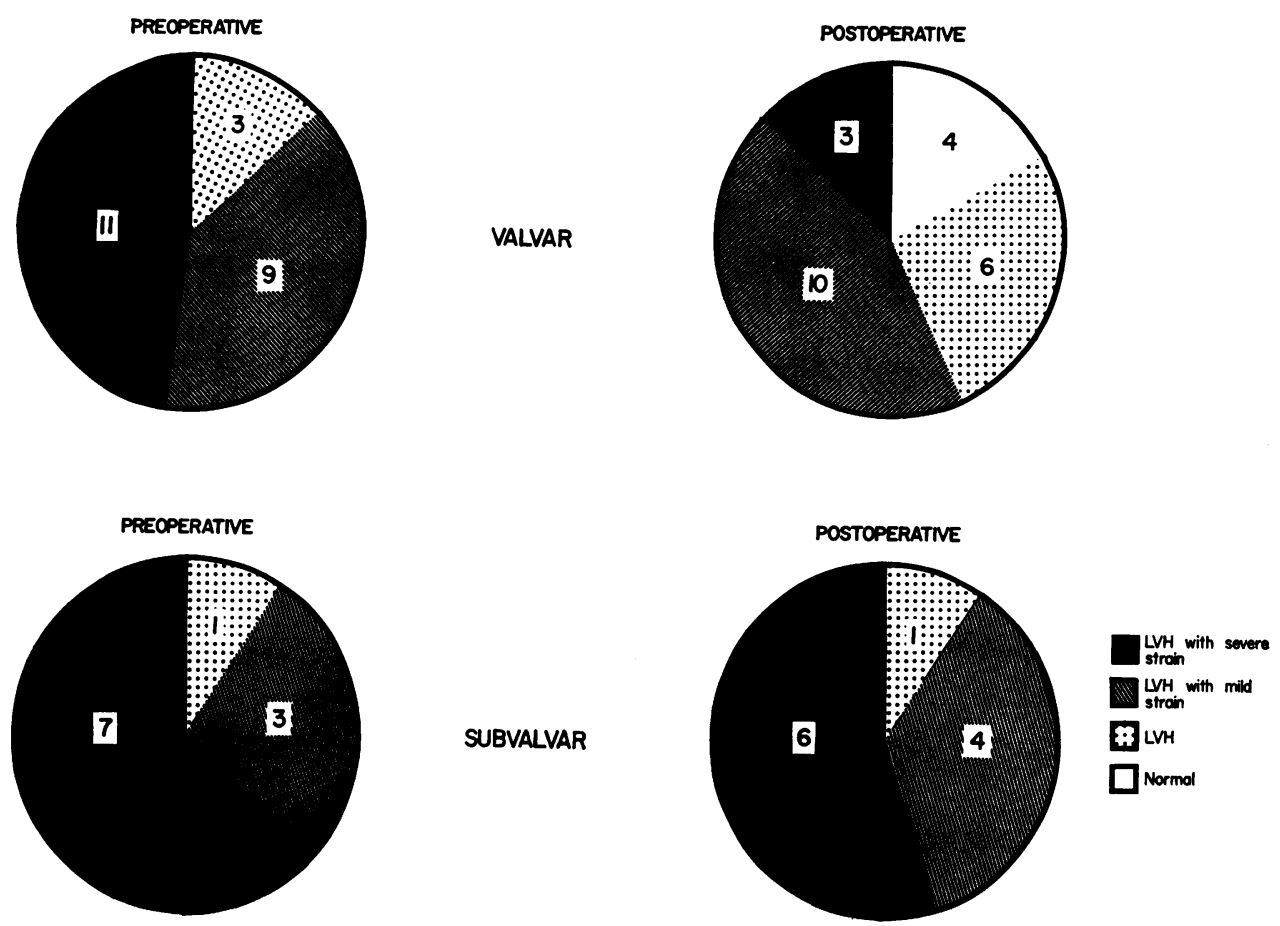

FIG. 2.-Comparison of electrocardiographic status pre- and post-operatively in 23 patients with valvar and 11 with subvalvar aortic stenosis.

Fig. 2 demonstrates the electrocardiographic status pre- and post-operatively. Left ventricular hypertrophy with severe strain is defined as sharp $T$ wave inversion with $S-T$ segment depression in lead 1 and in the left præcordial leads including V4. Left ventricular hypertrophy with mild strain is defined as minor $\mathrm{T}$ wave and $\mathrm{S}-\mathrm{T}$ segment abnormalities confined to V5 and V6. Left ventricular hypertrophy is considered to be present if the voltage in the left ventricular leads exceeds the maximum of our own normals (Alimurung et al., 1951). Pre-operatively all the patients had an abnormal electrocardiogram; slightly less than half of the valvar and more than half of the subvalvar group showed evidences of severe strain. Post-operatively 4 of the patients in the valvar group had a normal electrocardiogram. None of the subvalvar group has returned to normal at the time of the writing of this paper. Furthermore, now only 3 of the patients with valvar stenosis still show severe electrocardiographic changes and, incidentally, all of these are

TABLE II

Pre-operative and Post-operative left Heart Catheterization Data-Valvar Aortic Stenosis

\begin{tabular}{|c|c|c|c|c|c|c|c|}
\hline \multirow{2}{*}{ Patient } & \multirow{2}{*}{$\begin{array}{c}\text { Age at } \\
\text { operation }\end{array}$} & \multirow{2}{*}{$\begin{array}{c}\text { Follow up } \\
\text { interval } \\
\text { (months) }\end{array}$} & \multicolumn{2}{|c|}{ Peak systolic gradient $(\mathrm{mm} . \mathrm{Hg})$} & \multicolumn{2}{|c|}{ Aortic valve area $\left(\mathrm{cm} .^{2}\right)$} & \multirow{2}{*}{$\begin{array}{l}\text { Cardiographic } \\
\text { improvement }\end{array}$} \\
\hline & & & Pre-operative & Post-operative & Pre-operative & Post-operative & \\
\hline $\begin{array}{l}\text { D.H. } \\
\text { L.H. } \\
\text { M.D. } \\
\text { D.F. } \\
\text { G.H. } \\
\text { M.D. } \\
\text { G.O. }\end{array}$ & $\begin{array}{c}155 / 12 \\
155 / 12 \\
127 / 12 \\
98 / 12 \\
5 \\
19 / 12 \\
16\end{array}$ & $\begin{array}{l}42 \\
39 \\
38 \\
27 \\
25 \\
23 \\
22\end{array}$ & $\begin{array}{r}87 \\
60 \\
56 \\
65 \\
54 \\
110 \\
60\end{array}$ & $\begin{array}{r}65 \\
50 \\
0 \\
26 \\
40 \\
0 \\
14\end{array}$ & $\begin{array}{l}0.50 \\
1.10 \\
0.75 \\
0.51 \\
0.50 \\
0.22 \\
1.30\end{array}$ & $\begin{array}{l}1.07 \\
1.0 \\
\overline{1.20} \\
0.74 \\
\overline{1.90}\end{array}$ & $\begin{array}{l}\text { No } \\
\text { No } \\
\text { Yes } \\
\text { Yes } \\
\text { Yes } \\
\text { Yes } \\
\text { No }\end{array}$ \\
\hline
\end{tabular}


adolescents over 13 years of age. By contrast, only one of the subvalvar group showed appreciable improvement. It is interesting to note that the change in this 20 -year-old male did not occur until 30 months after complete relief of his aortic stenosis.

Seven patients with valvar stenosis and 6 patients with subvalvar stenosis have had right and left heart catheterizations one year after operation. Table II and Table III correlate the peak systolic gradient and calculated valve area with the trend of the most recent cardiogram in each case.

TABLE III

Pre-operative and Post-operative Left heart Catheterization Data-Subvalvar Aortic Stenosis

\begin{tabular}{|c|c|c|c|c|c|c|c|}
\hline \multirow{2}{*}{ Patient } & \multirow{2}{*}{$\begin{array}{c}\text { Age at } \\
\text { operation }\end{array}$} & \multirow{2}{*}{$\begin{array}{c}\text { Follow up } \\
\text { interval } \\
\text { (months) }\end{array}$} & \multicolumn{2}{|c|}{ Peak systolic gradient $(\mathrm{mm} . \mathrm{Hg})$} & \multicolumn{2}{|c|}{ Aortic valve area $\left(\mathrm{cm}^{2}\right)$} & \multirow{2}{*}{$\begin{array}{c}\text { Electro- } \\
\text { cardiographic } \\
\text { improvement }\end{array}$} \\
\hline & & & Pre-operative & Post-operative & Pre-operative & Post-operative & \\
\hline $\begin{array}{l}\text { E.C. } \\
\text { B.S. } \\
\text { D.F. } \\
\text { S.A. } \\
\text { R.M. } \\
\text { J.B. }\end{array}$ & $\begin{array}{rl}10 & 11 / 12 \\
20 & 5 / 12 \\
8 & 11 / 12 \\
15 & 5 / 12 \\
7 & 7 / 12 \\
9 & 2 / 12\end{array}$ & $\begin{array}{l}39 \\
38 \\
30 \\
22 \\
22 \\
19\end{array}$ & $\begin{array}{r}90 \\
55 \\
160 \\
40 \\
35 \\
50\end{array}$ & $\begin{array}{r}0 \\
0 \\
120 \\
0 \\
0 \\
45\end{array}$ & $\begin{array}{l}0.53 \\
1 \cdot 3 \\
0 \cdot 31 \\
0 \cdot 80 \\
0.58 \\
0.42\end{array}$ & $\begin{array}{l}\overline{-} \\
0.32 \\
\overline{-} \\
0.45\end{array}$ & $\begin{array}{l}\text { No } \\
\text { Yes } \\
\text { No } \\
\text { No } \\
\text { No } \\
\text { No }\end{array}$ \\
\hline
\end{tabular}

In the valvar group the gradient has been completely abolished or is trivial in 4 , and in 3 has been little affected; of these 3,2 had bicuspid aortic valves.

In the subvalvar group 4 patients have had the gradient completely abolished and in 2 there has been little change.

TABLE IV

Post-operative Aortic Valve Gradient Related to Cardiographic Change

\begin{tabular}{ll|l|c|c}
\hline & & & $\begin{array}{c}\text { Cardiographic } \\
\text { improvement }\end{array}$ \\
Gradient abolished & \{ & Valvar & 2 & 2 \\
Subvalvar & 4 & 1 \\
Gradient diminished & \{ & 3 & 2 \\
Valvar & 0 & 0 \\
Subvalvar & 2 & 0 \\
Valvar & Sradient unaffected & Subvalvar & 2 & 0 \\
\hline
\end{tabular}

Summarizing the relationship between the post-operative gradient and the post-operative electrocardiogram (Table IV), we found that of the 4 patients with subvalvar stenosis who had had their gradient completely abolished by surgery, only one had shown any cardiographic improvement and this was after a delay of $\mathbf{3 0}$ months. By contrast in the valvar group, there was good correlation between the post-operative cardiogram and the post-operative gradient in all but 1 of the 7 patients.

\section{Discussion}

About one-half of our patients with a clinical diagnosis of congenital aortic stenosis have been subjected to left heart catheterization. These patients either had electrocardiographic evidences of left ventricular "strain" or had symptoms (chest pain, fatigue, syncope) referable to aortic stenosis. These criteria for left heart catheterization were based on the findings of Reynolds et al. (1960), 
that sudden death due to aortic stenosis may occur either in subjects with severe electrocardiographic changes or even in the absence of such if symptoms are present. Analysis of recent reports (Kjellberg et al., 1955; Marquis and Logan, 1955; Downing, 1956; Braverman and Gibson, 1957; Morrow et al., 1958; Ongley et al., 1958) revealed an over-all mortality of 7.5 per cent out of 306 children with congenital aortic stenosis. In practically every one of these fatalities there was either left ventricular hypertrophy with strain or symptoms present. We feel, then, that although the cardiogram, as a sole criterion of severity, cannot be depended upon in a negative sense, if used in conjunction with symptomatology, patients may be correctly selected for left heart catheterization.

The selection of patients for surgery has been based upon the demonstration of a peak systolic gradient across the aortic valve of more than $50 \mathrm{~mm}$. $\mathrm{Hg}$ or a mean systolic ejection gradient of more than $30 \mathrm{~mm}$. Hg. We have regarded a calculated valve area of less than 0.5 square centimetres per square metre as an indication for surgery, a figure similar to that suggested by Dexter et al. (1958) and Morrow et. al. (1958). Where a patent ductus arteriosus has been present we have interpreted the degree of stenosis with regard to the increased flow through the aortic valve. Using these criteria, we found that about one-half of our patients selected for cardiac catheterization had lesions severe enough to warrant operative intervention. At operation every one of the patients was found to have significant aortic obstruction. We may thus state that the hæmodynamic criteria outlined signify the presence of severe aortic stenosis.

A small number of the remaining one-half proved to have trivial obstruction (less than $20 \mathrm{~mm}$. $\mathrm{Hg}$ peak systolic gradient): these are being followed at infrequent intervals. The remaining patients with a moderate gradient are being followed carefully with clinical and electrocardiographic reviews at six-monthly intervals: the parents of the latter group of patients have been warned that surgery may be indicated in the future.

It seems then that the criteria for patient selection for operation are valid. The indications for left heart catheterization are probably too broad since only half of the individuals subjected to this procedure proved to have critical stenosis. At the same time, since no other criteria for patient selection exists at the moment, we would prefer to study some children without severe stenosis rather than overlook one who would need surgical intervention. Of course we do not know whether some children not meeting the criteria for left heart catheterization may also have severe stenosis, but we are not aware of sudden death in any of a large number of patients with clinically mild aortic stenosis by our pre ent criteria within the past 10 years.

Where there has been a coexistent coarctation of the aorta we have electively relieved the more severe obstruction first. If the two lesions have seemed of equal severity, we have relieved the aortic stenosis first to avoid the stress of surgery on a heart with possibly compromised coronary flow.

In attempting to establish the diagnosis of subvalvar stenosis pre-operatively, we have only obtained the typical withdrawal tracing across the obstructed area in 5 out of 11 cases. Clinical features which we have found helpful in determining the site of the stenosis pre-operatively have been the absence of a systolic ejection click and the presence of an aortic diastolic murmur in most cases of aortic subvalvar stenosis. We have not found analysis of the second heart sound or the configuration of the systemic arterial pressure pulse useful, as suggested by Brofman and Feil (1952).

Although the differentiation of organic valvar and subvalvar stenosis from functional obstruction of the left ventricular outflow tract does not fall strictly within the framework of the present publication, we feel it is a diagnostic problem of prime importance. The salient points suggesting a diagnosis of "functional" aortic stenosis are: (1) family history (Brent et al., 1960); (2) late appearance of the murmur; (3) sharp upstroke in the carotid artery tracing in the face of hæmodynamically severe aortic stenosis (Brent et al., 1960); (4) a notch on the upstroke of the left ventricular tracing corresponding to the peak systolic pressure in the aorta, (5) the behaviour of the systemic arterial pressure pulse after premature beats (Brockenbrough et al., 1961). We have encountered within the past 10 years one case proven by autopsy and two in which we have made the diagnosis clinically. 
The risks of surgical treatment in our patients with congenital aortic stenosis seem closely to parallel the experience of others in predominantly adult patients. Harken et al. (1958) in a series of 100 adult patients with aortic stenosis operated upon by a trans-aortic procedure note a mortality of 16 per cent. Abelman and Ellis (1959) reporting on the same material note a clinical improvement rate of 74 per cent, 6 months to 4 years after operation. Other investigators cite similar experiences (Morrow et al., 1958; Baker and Somerville, 1959; Kirklin and Mankin, 1960; Gilbert et al., 1960).

Brock (1959) reporting the operative results in 16 cases of discrete congenital aortic subvalvar stenosis, notes that 3 patients died from the operation and states: "Almost without exception the stenotic element was severe and in several was very severe. Our experience does not support the comments sometimes made that subvalvar stenosis is often a mild lesion. In fact, it appears that it is a more severe lesion than congenital aortic valvar stenosis." Our own experience in 11 cases of subvalvar stenosis has been similar, and we also have been impressed by the severity of the disease at the time of operation. However, more striking has been the failure or extreme tardiness of the electrocardiogram to revert towards normal post-operatively even though the gradient is known in some patients to have been completely relieved.

Attempting to explain the poor electrocardiographic response to surgery in the subvalvar group, we have tried unsuccessfully to correlate the post-operative electrocardiogram with the length of cardiopulmonary bypass and with the length of potassium citrate cardioplegia. The subvalvar and valvar groups have been comparable in their average age at operation and in the duration of electrocardiogram changes pre-operatively. The subvalvar group had slightly worse electrocardiograms at the time of operation but the difference was not marked.

\section{CONCLUSIONS}

The prognosis of children who have had correction of aortic valvar stenosis seems good as judged by clinical, radiologic, electrocardiographic, and post-operative catheterization data. In cases of subvalvar stenosis the prognosis does not seem so favourable, particularly with respect to reversion of the electrocardiogram towards normal. We have encountered no case of subvalvar stenosis where the obstruction was mild, and we would suggest that where the diagnosis can be made, operation should be undertaken as early as possible, before electrocardiographic deterioration takes place.

\section{SUMMARY}

Forty-two patients with congenital aortic stenosis operated upon by cardiopulmonary bypass are reviewed. Two-thirds of the uncomplicated cases had valvar and one-third subvalvar stenosis.

There were 6 operative deaths, all but one in young infants or patients with complex lesions.

Among the survivors symptomatic improvement was uniform. Improvement in the electrocardiogram was noted in most of the patients with valvar but only in one of the patients with subvalvar stenosis.

Post-operative catheterization in 13 patients showed significant improvement in 8.

The lack of correlation between hæmodynamic and electrocardiographic improvement in the subvalvar group is stressed.

Indications for left heart catheterization and surgery in patients with a clinical diagnosis of aortic stenosis are outlined.

The authors wish to record their thanks and appreciation to Dr. Abraham M. Rudolph, who carried out the bulk of the hæmodynamic studies, for his help and criticism.

\section{REFERENCES}

Abelmann, W. H., and Ellis, L. B. (1959). Ann. intern. Med., 51, 449.

Alimurung, M. M., Joseph, L. G., Nadas, A. S., and Massell, B. F. (1951). Circulation, 4, 420.

Baker, C., and Somerville, J. (1959). Guy's Hosp. Rep., 108, 101. 
Braverman, I. B., and Gibson, S. (1957). Amer. Heart J., 53, 487.

Brent, L. B., Alburan, A., Fisher, D. L., Moran, T. J., Myers, J. D., and Taylor, W. J. (1960). Circulation, $21,167$. Brock, R., Milstein, B. B., and Ross, D. N. (1956). Thorax, 11, 163. (1959). Guy's Hosp. Rep., 108, 144.

Brockenbrough, E. C., Braunwald, E., and Morrow, A. G. (1961). Circulation, $23,189$.

Brofman, B. L., and Feil, H. (1952). Circulation, 6, 817.

Dexter, L., Harken, D. E., Cobb, L. A., Novack, P., Schland, R. C., Phinney, A. O., Jr., and Haynes, F. W. (1958). Arch. intern. Med., 101, 254.

Downing, D. F. (1956). Circulation, 14, 188.

Gilbert, J. W., Morrow, A. G., and Braunwald, E. (1960). Ann. Surg., 151, 1.

Gross, R. E. (1959). New Eng. J. Med., 260, 1047.

Harken, D. E., Black, H., Taylor, W. J., Thrower, W. B., and Soroff, H. S. (1958). J. thorac. Surg., $36,759$.

Kirklin, J. W., and Mankin, H. J. (1960). Circulation, 21, 578.

Kjellberg, S. R., Mannheimer, E., Rudhe, U., and Jonsson, B. (1955). Diagnosis of Congenital Heart Disease. Year Book Publishers: Chicago, p. 496.

Marquis, R. M., and Logan, A. (1955). Brit. Heart J., 17, 373.

Morrow, A. G., Sharp, E. H., and Braunwald, E. (1958). Circulation, 18, 1091. Braunwald, E., Ross, J. Jr. (1960). Arch. intern. Med., 105, 645.

Ongley, P. A., Nadas, A. S., Paul, M. H., Rudolph, A. M., and Starkey, G. W. B. (1958). Pediatrics, $21,207$.

Reynolds, J. L., Nadas, A. S., Rudolph, A. M., and Gross, R. E. (1960). New Eng. J. Med., $262,276$.

Rudolph, A. M., and Cayler, G. G. (1958). Pediat. Clin. N. Amer., 5, 907.

Zimmerman, H. A., Scott, R. W., and Becker, N. D. (1950). Circulation, 1, 357. 